\title{
Severe Antiretroviral Therapy-Induced Toxic Epidermal Necrolysis in a Child
}

\author{
Joseph M. Norris Laura H. Stuttaford Lyn F. Dowds \\ David Gordon Memorial Hospital, Livingstonia, Malawi
}

\section{Key Words}

Antiretroviral therapy $\cdot$ Child $\cdot$ Lyell's syndrome $\cdot$ Nevirapine $\cdot$ Toxic epidermal necrolysis

\begin{abstract}
Toxic epidermal necrolysis (TEN) is a rare and life-threatening condition characterised by extensive epidermal detachment and mucosal erosion. Adverse drug reaction is a strongly correlated causative factor and TEN is currently considered the most severe end of a spectrum of drug-induced mucocutaneous diseases, including Stevens-Johnson syndrome. Attaining an accurate and detailed patient history is critical for identifying potential causative agents, which can prove challenging; particularly in cultures such as that of Malawi. TEN lacks definitive management and the use of immunomodulation, such as with corticosteroids and intravenous immunoglobulin, remains controversial. We report a fascinating case of TEN associated with antiretroviral therapy. A 10-year-old female was given a combination of antiretroviral drugs (lamivudine, nevirapine and stavudine) as postexposure prophylaxis, having been raped. The child subsequently developed TEN and presented to our remote hospital in Malawi, where she was treated entirely with supportive therapy. This is an excellent example of difficult disease management in a limited-resource setting and provides reassuring evidence to clinicians of similar circumstance. To our knowledge, this is the first case report of antiretroviral therapy-induced TEN in a child.
\end{abstract}

\section{Introduction}

Toxic epidermal necrolysis (TEN or Lyell's syndrome) is a very rare $(0.05-2$ cases per million per year) [1] and potentially lethal adverse reaction to drugs or infection. We describe a fascinating case of a 10-year-old female admitted to our remote and under-resourced hospital in Malawi, having developed TEN associated with antiretroviral therapy; notably, with the non-nucleoside reverse transcriptase inhibitor, 
nevirapine. To our knowledge, this is the first case report of antiretroviral therapyinduced TEN in a child.

\section{Case Report}

A 10-year-old female attended a clinic in rural Malawi, seven days after having been raped by a 21-year-old male. The HIV-status of her attacker was unknown and so given Malawi's HIV epidemic (10-12.1\% for adults aged 15-49 in 2009) [2] she was prescribed a fixed-dose combination of antiretroviral drugs, including lamivudine $150 \mathrm{mg}$, nevirapine $200 \mathrm{mg}$ and stavudine $30 \mathrm{mg}$, as postexposure prophylaxis. Ten days later, she presented systemically unwell with a three day history of fever, stomatitis and widespread pruritic rash. Her condition rapidly deteriorated and so she was transferred to our hospital.

Examination revealed truncal epidermal loss and raw, oozing dermis (ig. 1a). Remaining epidermis featured irregular erythematous zones and flaccid bullae (fig. 1b). Nikolsky's sign (tangential pressure cleaves full-thickness epidermis) and Asboe-Hansen sign (pressure extends blister laterally) were both positive, being indicative, but not pathognomonic, of TEN. Admission observations showed: heart rate was regular (122 beats/min), blood pressure was $102 / 70 \mathrm{~mm} \mathrm{Hg}$, axillary temperature was $38.7^{\circ} \mathrm{C}$, respiratory rate was 34 breaths/min and peripheral $\mathrm{O}_{2}$ saturation was $98 \%$. Available laboratory analyses revealed: haemoglobin was $12.6 \mathrm{~g} / \mathrm{dl}$ and that she had a nonreactive HIV-status. Clinical diagnosis of TEN was made through confirmation of antiretroviral therapy prescription and with $>60 \%$ body surface area epidermal detachment, by modified Lund and Browder chart. Absent histopathology services made tissue diagnosis impossible, but punch biopsy showing full-thickness epidermal necrosis was to be expected.

Management was directed by poor-resource availability at our hospital. All previous medication was terminated and intravenous Ringer's lactate $1 \mathrm{l}$ and pethidine $25 \mathrm{mg}$ were administered in an isolation room. A simple burn recovery bed-cradle was arranged to minimise epithelial and dermal contact with insulating blankets. Meticulous fluid-balance failed as urinary catheter insertion removed excessive urethral meatal epidermis. Supportive therapy was continued for 21 days, with graduated change to oral fluid, ibuprofen $200 \mathrm{mg}$ and paracetamol $500 \mathrm{mg}$. Local food was supplemented to address protein-deficiency and silver sulfadiazine was regularly applied to skin for infection prophylaxis (fig. 1c). Ophthalmic opinion was sought and a combination eyedrop of tobramycin $0.3 \%$, dexamethasone $0.1 \%$ and benzalkonium chloride $0.01 \%$ was prescribed. Painful erosions of conjunctival, oral and genital mucosa appeared within $24 \mathrm{~h}$ of admission (fig. 2a), whilst re-epithelialisation began after ten days. Protein-deficiency oedema and anaemia (haemoglobin was $6.5 \mathrm{~g} / \mathrm{dl}$ ) occurred and resolved during the latter stages of healing (fig. 2f). Full recovery took 28 days, with some cutaneous scarring and abnormal pigmentation as final sequelae (fig. 1e).

\section{Discussion}

In 1956, Lyell described TEN as an 'eruption resembling skin scalding' and suggested potential pathomechanism: epidermal necrosis/lysis secondary to toxaemia [3]. Today, TEN is perceived as the most severe end of a spectrum of systemic drug-induced mucocutaneous conditions, including Stevens-Johnson syndrome (table 1). Immmunopathogenesis involves widespread keratinocyte apoptosis following interaction between the death receptor Fas and Fas ligand (CD95), in addition to the activation of the perforin/granzyme pathway [4].

TEN has very poor prognosis (mortality $30-50 \%$ ) attributed to multiorgan failure and sepsis. A recent study described lower mortality in children [5] but significant morbidity makes dermatological, ophthalmic and paediatric consultation highly advisable. We recommend the severity stratification 'SCORTEN' scale, for accurate prognostic indication in sufficiently-resourced centres [6]. One negative aspect of this 
scale, however, is the underemphasis of the extent of epidermal detachment. Patients with $100 \%$ body surface area involvement have far worse prognoses than those with only $30 \%$ involvement - though both groups of patients rank equally, in terms of SCRORTEN points.

Attaining detailed patient history and terminating offending agents is essential. We experienced difficulties in this area as initial information was scarce, so TEN associated with traditional African medicine was briefly considered. Lim and Thirumoorthy recently reported a case of traditional Chinese medicine-induced TEN [7] and so whilst there are no currently recorded cases associated with African medicine, we suggest that this is a ripe area for research.

Over 100 drugs have been associated with TEN. Risk of toxiderma is very high with antiretroviral drugs, especially in HIV-positive patients, who are 1,000 times more likely to develop TEN than noninfected patients [8]. In our case, the culprit was almost certainly the fixed combination of antiretroviral drugs (lamivudine, nevirapine and stavudine). Lamivudine and stavudine are relatively safe, with mild adverse cutaneous reactions being rarely reported. In contrast nevirapine is notorious, causing TEN in approximately $0.3 \%$ of patients [9] and is thus the likely single precipitant in our patient. All six cases of nevirapine-induced TEN in the existing literature are adults, who were treated in large university hospitals (table 2). Prior to our case, no report describes nevirapine or antiretroviral therapy-induced TEN in a child.

Association between antiretroviral therapy/nevirapine and TEN is reinforced here, thus we implore prescribers to exercise pharmacovigilance. Prescription of any form of postexposure prophylaxis was inappropriate for our patient, as she fell outside of the designated $72 \mathrm{~h}$ prophylactic window, by $96 \mathrm{~h}$. Additionally, the drugs given were merely standard Malawian antiretroviral drugs (unsuitable for postexposure prophylaxis). Lastly, the dose prescribed was neither the paediatric nor the loading dose - adding to the collection of serious errors.

Once the culprit drug is removed, the patient should be rigorously supported and our success here illustrates this as excellent stand-alone therapy. Fluid and analgesia are mandatory, whilst antimicrobials are beneficial, as evidenced by absent cutaneous infection in our patient. Immunomodulators such as cyclosporine, $N$-acetylcysteine, and corticosteroids have been trialled with varying success, but are clearly unaffordable in rural, tropical healthcare settings. Reports of hastened recovery periods in patients given IVIG exist [10-12], but again this is limited by resource availability. Clinicians must utilise what is available to them and so in other limited-resource settings, inventive treatments for TEN such as autoclaved banana leaf dressings, have been employed [15]. Currently, there are no evidence-based standard guidelines for the treatment of TEN and the literature consists of small uncontrolled series and few case reports, of which ours adds to. These anecdotal reports highlight the need for a large, randomised control trial to ascertain definitive, first-line management.

To the best of our knowledge, this is the first reported case of antiretroviral therapyinduced TEN in a child. This report demonstrates how under-resourced rural African hospitals are, whilst still being able to provide the intense supportive care required for TEN management. Clinicians faced with comparable scenarios should be reassured, 
whilst those in the developed world should pause to consider the challenges of tropical dermatology.

\section{Acknowledgement}

The authors thank Dr. Charles R. Darley for his insightful advice.

\section{Disclosure Statement}

The authors have no conflicts of interest to declare.

Table 1. Spectrum of severe cutaneous adverse drug reactions [4]

\begin{tabular}{lllll}
\hline & EMM & SJS & SJS/TEN overlap & TEN \\
\hline BSA epidermal detachment & $1-2 \%$ & $<10 \%$ & $10-30 \%$ & $>30 \%$ \\
\hline Typical target lesions & Present & Absent & Absent & Absent \\
\hline Atypical target lesions & Present - raised & Present - flat & Present - flat & Present - flat \\
\hline Confluent purpuric macules & Absent & Present & Present & Occasionally present \\
\hline Important differential diagnoses & Staphyloccocal scalded skin syndrome; autoimmune blistering diseases \\
\hline BSA = Body surface area; EMM = erythema multiforme majus; SJS = Stevens-Johnson syndrome. & \\
\hline
\end{tabular}


Table 2. Existing case reports of nevirapine-induced TEN

\begin{tabular}{|c|c|c|c|c|c|}
\hline $\begin{array}{l}\text { Author } \\
\text { (year) }\end{array}$ & $\begin{array}{l}\text { Age } \\
\text { years } \\
(\operatorname{sex})\end{array}$ & $\begin{array}{l}\text { Total } \\
\text { ED } \\
(\%)\end{array}$ & Treatment & $\begin{array}{l}\text { Treatment } \\
\text { duration } \\
\text { (days) }\end{array}$ & $\begin{array}{l}\text { Adverse events } \\
\text { (outcome) }\end{array}$ \\
\hline $\begin{array}{l}\text { Phan et al. } \\
\text { (1999) [10] }\end{array}$ & 31 (male) & 50 & Supportive, IVIG, fluconazole, acyclovir, cephazolin & 14 & $\begin{array}{l}\text { (Complete } \\
\text { resolve) }\end{array}$ \\
\hline \multirow[t]{2}{*}{$\begin{array}{l}\text { Cattelan et al. } \\
\text { (2001) [11] }\end{array}$} & 26 (female) & $45-50$ & Supportive, IVIG, prednisone & 72 & $\begin{array}{l}\text { (Complete } \\
\text { resolve) }\end{array}$ \\
\hline & 22 (female) & $30-35$ & Supportive & 35 & $\begin{array}{l}\text { (Complete } \\
\text { resolve) }\end{array}$ \\
\hline $\begin{array}{l}\text { Claes et al. } \\
(2004)[12]\end{array}$ & 39 (male) & $80-90$ & $\begin{array}{l}\text { Supportive, chlorhexidine, fluconazole, clindamycin, } \\
\text { acyclovir, paracetamol, IVIG, } N \text {-acetylcysteine }\end{array}$ & 35 & Toxic hepatitis \\
\hline $\begin{array}{l}\text { Leng et al. } \\
(2008)[13]\end{array}$ & 32 (male) & 100 & Supportive & 30 & (Death) \\
\hline $\begin{array}{l}\text { Sachdev et al. } \\
\text { (2011) [14] }\end{array}$ & 34 (male) & $\begin{array}{l}\text { Not } \\
\text { stated }\end{array}$ & $\begin{array}{l}\text { Ophthalmic: cephazolin-sodium, tobramycin-sulfate, } \\
\text { propamedine-isothionate, chlorhexidine-gluconate, } \\
\text { carboxymethylcellulose, homatropine-hydrobromide, } \\
\text { amniotic membrane transplantation }\end{array}$ & not stated & $\begin{array}{l}\text { Bilateral } \\
\text { microbial } \\
\text { keratitis } \\
\text { (complete } \\
\text { resolve) }\end{array}$ \\
\hline Summary & 30.7 (male) & 63 & Various & 37.2 & Various \\
\hline
\end{tabular}

$\mathrm{ED}=$ Epidermal detachment; IVIG = intravenous immunoglobulin.
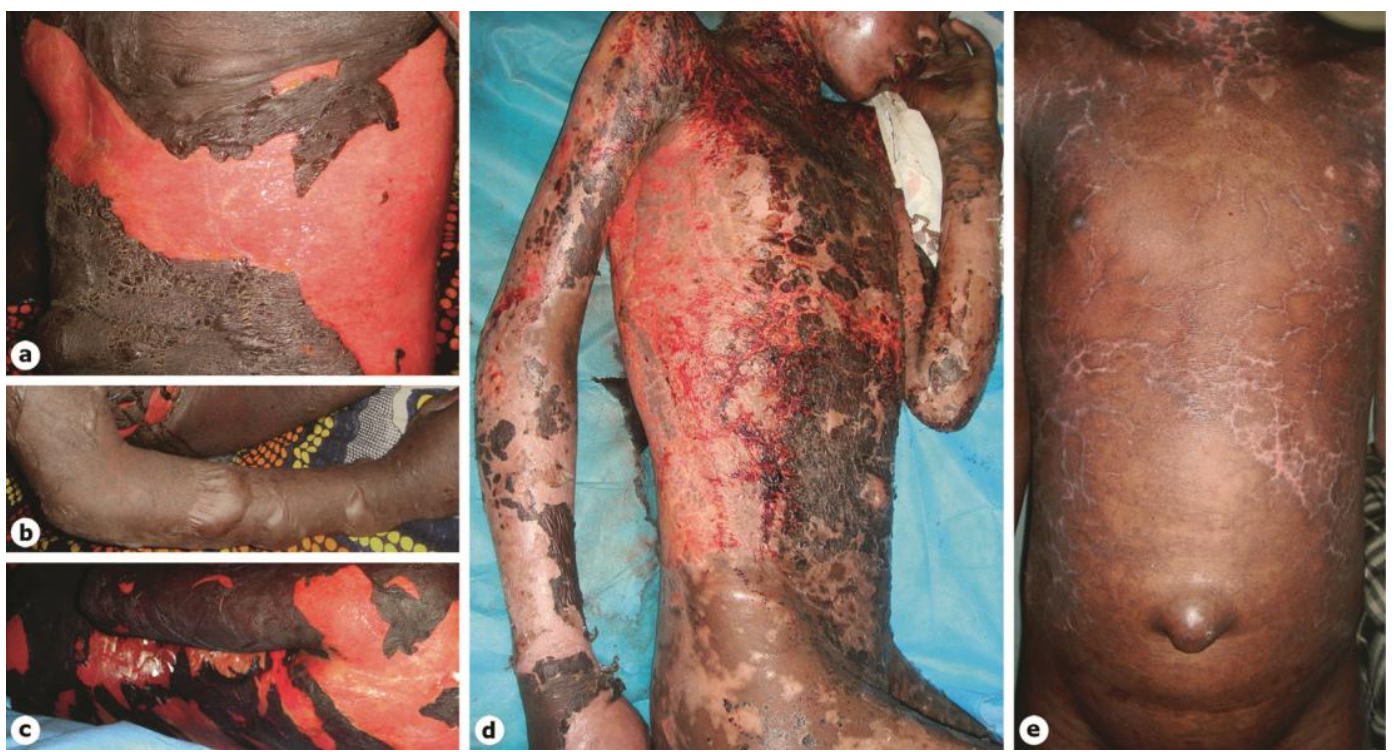

Fig. 1. a Truncal epidermal necrolysis and $\mathbf{b}$ flaccid bullae on right upper limb, on admission. c Silver sulfadiazine application, day 7. d Extensive lesioning, day 14. e Re-epithelialisation with altered pigmentation, day 21. Incidental umbilical hernia was untreated. 

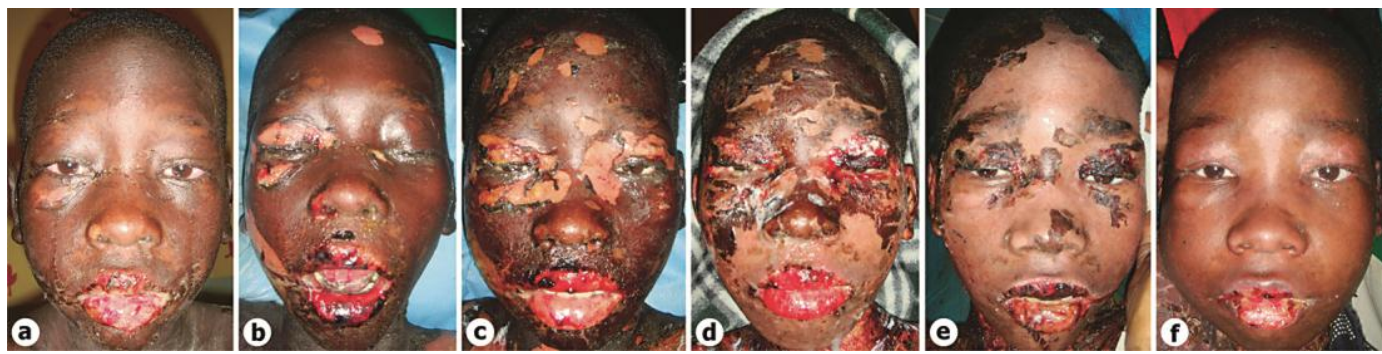

Fig. 2. Facial chronology. a Nikolsky's sign under right eye and haemorrhagic oral erosions, on admission. b Eyelids oedema and lip necrosis, day 5. c Epidermal stripping and ulcerated conjunctivae, day 9. d Silver sulfadiazine application, day 13. e Re-epithelialisation, day 17 f Predominantly healed, with mild facial oedema, day 21.

\section{References}

-1 Barvaliya M, Sanmukhani J, Patel T, Paliwal N, Shah H, Tripathi C: Drug-induced Stevens-Johnson syndrome (SJS), toxic epidermal necrolysis (TEN), and SJS-TEN overlap: a multicentric retrospective study. J Postgrad Med 2011;57:115-119.

2 UNAIDS: Epidemiological Factsheet of HIV and AIDS, 2009 (Malawi). Geneva, UNAIDS, 2009, p 1.

3 Lyell A: Toxic epidermal necrolysis: an eruption resembling scalding of the skin. Br J Dermatol 1956;68:355-361.

4 Mockenhaupt M: The current understanding of Stevens-Johnson syndrome and toxic epidermal necrolysis. Expert Rev Clin Immunol 2011;7:803-813.

5 Finkelstein Y, Soon GS, Acuna P, George M, Pope E, Ito S, Shear NH, Koren G, Shannon MW, GarciaBournissen F: Recurrence and outcomes of Stevens-Johnson syndrome and toxic epidermal necrolysis in children. Pediatrics 2011;128:723-728.

-6 Bastuji-Garin S, Fouchard N, Bertocchi M, Roujeau JC, Revuz J, Wolkenstein P: SCORTEN: a severity-ofillness score for toxic epidermal necrolysis. J Invest Dermatol 2000;115:149-153.

-7 Lim YL, Thirumoorthy T: Serious cutaneous adverse reactions to traditional Chinese medicines. Singapore Med J 2005;46:714-717.

-8 Rzany B, Mockenhaupt M, Stocker U, Hamouda 0, Schöpf E: Incidence of Stevens-Johnson syndrome and toxic epidermal necrolysis in patients with the acquired immunodeficiency syndrome in Germany. Arch Dermatol 1993;129:1059.

-9 Fagot JP, Mockenhaupt M, Bouwes-Bavinck JN, Naldi L, Viboud C, Roujeau JC; EuroSCAR Study Group: Nevirapine and the risk of Stevens-Johnson syndrome or toxic epidermal necrolysis. AIDS 2001;15:1843.

10 Phan TG, Wong RC, Crotty K, Adelstein S: Toxic epidermal necrolysis in acquired immunodeficiency syndrome treated with intravenous gammaglobulin. Australas J Dermatol 1999;40:153-157.

11 Cattelan AM, Trevenzoli M, Sasset L, Sgarabotto D, Lanzafame M, Meneghetti F: Toxic epidermal necrolysis induced by nevirapine therapy: description of two cases and review of the literature. J Infect 2001;43:246-249.

12 Claes P, Wintzen M, Allard S, Simons P, De Coninck A, Lacor P: Nevirapine-induced toxic epidermal necrolysis and toxic hepatitis treated successfully with a combination of intravenous immunoglobulins and N-acetylcysteine. Eur J Intern Med 2004;15:255-258.

$\checkmark 13$ Leng K, Lonsdorf A, Hartmann M: Fatal outcome of nevirapine-associated toxic epidermal necrolysis. Int J STD AIDS 2008;19:642-643.

14 Sachdev R, Bansal S, Sinha R, Sharma N, Titiyal JS: Bilateral microbial keratitis in highly active antiretroviral therapy-induced Stevens-Johnson syndrome and toxic epidermal necrolysis: a case series. Ocul Immunol Inflamm 2011;19:343-345.

15 Srinivas CR, Sundaram VS, Raju BA, Prabhu SK, Thirumurthy M, Bhaskar AC: Achieving asepsis of banana leaves for the management of toxic epidermal necrolysis. Indian J Dermatol Venereol Leprol 2006;72:201-202. 